\title{
BMJ Open Quality Near Me at Home: codesigning the use of video consultations for outpatient appointments in patients' homes
}

\author{
Michelle Beattie, ${ }^{1}$ Clare Morrison, ${ }^{2,3}$ Rebecah MacGilleEathain, ${ }^{4}$ Nicola Gray, ${ }^{5}$ \\ Julie Anderson ${ }^{5}$
}

To cite: Beattie M, Morrison C, MacGilleEathain $\mathrm{R}$ et al. Near Me at Home: codesigning the use of video consultations for outpatient appointments in patients' homes. BMJ Open Quality 2020;9:e001035. doi:10.1136/ bmjoq-2020-001035

Received 29 May 2020 Revised 9 August 2020 Accepted 18 August 2020

Check for updates

(c) Author(s) (or their employer(s)) 2020. Re-use permitted under CC BY-NC. No commercial re-use. See rights and permissions. Published by BMJ.

${ }^{1}$ Department of Nursing and Midwifery, University of the Highlands and Islands, Inverness, UK

${ }^{2}$ North \& West Highland, NHS Highland, Ross-shire, UK

${ }^{3}$ Technology Enabled care Programme, Scottish

Government, Edniburgh, UK

${ }^{4}$ Nursing and Midwifery, University of the Highlands and Islands, Inverness, UK

${ }^{5}$ Scottish Improvement Science Collaborating Centre, School of Health Sciences, University of Dundee, Dundee, UK

Correspondence to Dr Michelle Beattie; michelle.beattie@uhi.ac.uk

\section{ABSTRACT}

Reforming the delivery of outpatient appointments (OPA) was high on the healthcare policy agenda prior to COVID-19. The current pandemic exacerbates the financial and associated resource limitations of OPA. Videoconsulting provides a safe method of real-time contact for some remotely residing patients with hospitalbased clinicians. One factor in failing to move from introduction of service change to its general adoption may be lack of patient and public involvement. This project, based in the largest Island in the Inner Hebrides of Scotland, aimed to codesign the use of the NHS Near Me video consulting platform for OPA to take place in the patient's home. A codesign model was used as a framework. This included: step 1-presenting a process flow map of the current system of using Near Me to public participants and establishing their ideas on various steps in the process, step 2-conducting numerous Plan, Do, Study, Act (PDSA) tests and creating a current process flow diagram based on learning and step 3-conducting telephone interviews and thematic analysis of transcripts $(n=7)$ to explore participants' perceptions of being involved in the codesign process. Twenty-five adaptations were made to the Near Me at Home video appointment process from participants' PDSA testing. Four themes were identified from thematic analysis of participants' feedback of the codesign process, namely: altruistic motivation, valuing community voices, the usefulness of the PDSA cycles and the power of 'word of mouth'. By codesigning the use of Near Me with people living in a remote area of Scotland, multiple adaptations were made to the processes to suit the context in which Near Me at Home will be used. Learning from testing and adapting with the public will likely be useful for others embarking on codesign approaches to improve spread and sustainability of quality improvement projects.

\section{PROBLEM}

Delivering the care people need, when they need it, is now more challenging than ever before. $^{12}$ The demographic, societal and financial factors impacting on health and social care services have been well rehearsed, with the demand for services commonly outweighing the available resource..$^{2-4}$ Prior to the outbreak of COVID-19, outpatient appointments (OPA) were the most common form of acute clinical contact with up to $70 \%$ of all hospital activity carried out in this way. ${ }^{5}$

OPA usually involve a brief physical face-toface appointment with a consultant, specialist doctor, nurse, or allied health professional in a hospital or clinic setting. Patient challenges associated with OPA include travelling, time off work and/or caring responsibilities. Clinicians may also need to travel to remote areas for satellite OPA clinics. There are associated financial implications for patients, as well as healthcare organisations who reimburse patients' and clinicians' travel costs. Travelling also contributes to the carbon footprint and associated environmental pollution. ${ }^{6}$ These challenges are exacerbated in remote and rural locations. NHS Highland serves a population of around 320000 distributed over a $32500 \mathrm{~km}^{2}$ land mass. ${ }^{7}$ This requires many patients to travel significant distances to attend OPA in the only acute district hospital in Inverness. The net result is that patients often travel several hours for a brief appointment. For example, patients may need to travel from Skye to Inverness (over 100 miles by road, taking on average 3 hours each way) for a $10 \mathrm{~min}$ OPA. This, understandably, can lead to patients being dissatisfied with the service.

The project described here took place before the COVID-19 pandemic. COVID-19 has added another layer of complexity and complication, ${ }^{8}$ including requirements to ensure safe physical distancing, thus reducing clinic capacity, and increased infection risks from attending the hospital environment. The current COVID-19 pandemic has therefore added stress to an already stretched system by further restricting access and faceto-face physical contact. Growing pressure to address urgent diagnostic and surgical needs requires healthcare services to think differently and design services in radical new ways. Innovative ways of delivering services also create opportunities to improve the way care 
is delivered to people; in this case, supporting the existing National Health Service (NHS) policy priority to radically reform outpatient services and deliver care closer to home, through the use of information technology (IT) ${ }^{9}$ Hospitals have also reported that, during the height of the pandemic, many OPA staff were redeployed to other clinical areas, having a further impact on the capacity to meet the growing demand from the backlog of suspended services. Describing this innovation is therefore timely.

Videoconsulting provides a method of real-time faceto-face contact via IT equipment to connect remotely residing patients to hospital based clinicians, therefore reducing the necessity to travel. ${ }^{10}$ In December 2017, NHS Highland began testing and implementing the use of Near Me, a video-consulting option for OPA derived from Attend Anywhere technology. ${ }^{11}$ CM initially used the Attend Anywhere platform from January 2017 to develop a pharmacy consulting service for remote and rural pharmacy, ${ }^{12}$ which enabled patients living in rural locations to have a consultation with a pharmacist over 100 miles away using telehealth. This project led to the realisation of the potential use for OPA. CM subsequently led the development and implementation of Near Me for OPA video consulting across NHS Highland. NHS Near Me was devised to minimise patient travel between the central urban hospital and remote NHS clinics, with patients attending a remote clinic and clinicians linking in from the central urban hospital. In order to maximise access to services and provide care closer to home, there was a need to test and implement the use of Near Me in peoples' homes.

Traditionally within healthcare, it has been commonplace for new innovations to be 'rolled out' to other areas, with minimal consideration of the contextual factors that influence the uptake or sustainability of an initiative. ${ }^{13-15}$ However, it is now recognised that you cannot just 'lift and shift' an intervention from one setting to another, without due consideration of the environment's influence on the initiative and the complex and dynamic nature of healthcare systems. ${ }^{16}$ Recognising NHS Highland's commitment to quality improvement (QI) approaches, the initial development of Near Me and subsequent extension to the home environment was conducted using QI methodologies, incorporating codesign. Patients and the public have not always been involved in designing healthcare services, yet evidence suggests that their perspectives are unique and if used effectively can improve implementation and sustainability. ${ }^{17-19}$ This project aimed to codesign the use of NHS Near Me to enable video consultations with specialists to take place in the patient's home.

\section{BACKGROUND}

Telemedicine and videoconsulting have been used in healthcare to facilitate management of long-term conditions for over a decade. ${ }^{2021}$ Within the literature, there is a growing body of evidence that supports these approaches and explores the benefits and limitations.
A systematic review of teleconsultation and videoconsulting in diabetic care services found that videoconsulting maintained quality of care while producing cost saving. ${ }^{22}$ A mixed-method study exploring the implementation of video OPA consultations in three clinical specialities (diabetes, diabetes antenatal and cancer surgery) found that the method appeared safe and popular for some patients and staff. ${ }^{23}$ The study did highlight technical challenges, including poor audio and visual quality, and the support required to install Skype. The study also identified issues in relation to a lack of booking and follow-up processes. A cluster randomised controlled trial (RCT) in the use of telehealth and telecare (including video consultations) in the NHS found that the RCT method was in conflict with implementation as the research design did not allow for iterative adaptations during the trial. ${ }^{24}$ Their findings highlight the importance of local contextual factors and the necessity for incremental implementation of telehealth and telecare interventions. A further study exploring barriers to integrating wider telehealth solutions for chronic disease management concluded that user-centred approaches to care are needed. ${ }^{25}$ While this project does not establish the effectiveness of video consultation, it does seek to use codesign to address end user involvement and addresses the necessity for incremental testing and adaptations to context, which have been highlighted as issues in the existing literature.

NHS Near Me uses technology to enable patients to have virtual consultations using a computer, smartphone or tablet via an internet connection. Prior to this project commencing in 2018, NHS Near Me had been successfully used in NHS Highland remote clinics. This earlier work had demonstrated excellent visual and sound quality, addressing many of the acknowledged acceptability barriers. This had enabled the creation of standard operating procedures for patient booking and flow for multiple specialities. This foundational work also addressed many of the technical and logistical challenges identified in prior studies of video consultation use. ${ }^{22}{ }^{23}$ NHS Near Me had only been used in NHS clinics as opposed to peoples' homes prior to this project, which ran between October 2018 and April 2019.

The Isle of Skye, the largest island in the Inner Hebrides of Scotland, was selected for the codesign of Near Me at Home for three reasons. First, there was a lengthy commute to the main OPA area (approximately a 6 hour round trip) and all the inherent challenges this brought to a predominantly ageing community. Second, the Isle of Skye was known to have variable digital connectivity. And third, the people of Skye had been vocal about the impact on their local community of other NHS changes ${ }^{26}$; therefore, the project provided an opportunity to connect with the community. The project aimed to codesign with the people of Skye systems and processes for NHS Near Me to enable video consultations with specialists to take place in the patient's home. 


\section{DESIGN}

The term codesign is used here to describe the process of activities and decision-making shared between the public and healthcare professionals to design a new product or service. ${ }^{27}$ All codesign approaches work with the theory that designing interventions with end users improves fidelity and implementation. The three-stage approach described here has been used with various types and scales of community participation and codesign work. ${ }^{28}$

Stage 1: inspiration-learning, valuing and trusting everyone's views and ideas.

Stage 2: ideation-identifying, testing and iteration based on learning from multiple ideas.

Stage 3: implementation-building partnerships and implementing the new idea/service.

\section{STRATEGY}

\section{Recruitment}

A public information session about the use of Near Me and the opportunity to codesign Near Me at Home in Skye was advertised in the local newspaper and on social media. At the public information session, a power point presentation was delivered by $\mathrm{CM}$ and $\mathrm{MB}$ on the use of Near Me and the plans to codesign its use with the people of Skye. The session also included CM, MB and LMac providing one-to-one opportunities for attendees to test the use of Near Me on an Ipad. Information was presented to describe which components of Near Me at Home were fixed (ie, the technology) and which were flexible (how the local community and NHS Highland can best use it). It was essential to be clear about what aspects of the intervention could and could not be codesigned to ensure that everyone involved had a clear purpose and tokenism was avoided. ${ }^{29}$ Interested participants completed a contact form. Additionally, a previous NHS public information session (not about Near Me) gathered contact details for adults living in Skye who wanted to be involved in future service redesign or research. Following the public information session on Near Me, both people who completed a contact form and those who were on a previous contact list were sent a participant information leaflet. Those wishing to participate in codesigning the use of Near Me at Home responded by telephone or email.

\section{Stage 1: inspiration}

Five participants responded to the telephone or email contact and attended an inspiration workshop, which was facilitated by $\mathrm{CM}$ and MB (both have clinical and service redesign expertise) in Skye. Participants were members of the public residing in Skye. Some participants could be defined as 'patients' as they may have had a forthcoming or previously scheduled OPA, but none were inpatients. Written consent was obtained before the session was audio recorded. A process flow map of the current process of using NHS Near Me was presented to the group (online supplementary additional file 1: process flow maps). Participants shared their ideas, such as the potential of reordering steps within the process and devising alternative and additional steps. The workshop ended with participants agreeing to test aspects of the process, as well as identifying or sharing information through a snowball approach to other members of the public and public groups. The purpose of sharing information was to inform other members of the community about the Near Me at Home service and to identify others willing to test and provide feedback on various aspects of Near Me use.

\section{Stage 2: ideation}

Plan, Do, Study, Act (PDSA) cycles were conducted for ideas identified in stage 1 , for testing and learning. PDSA cycles are useful to involve and engage participants in change. ${ }^{30}$ Multiple PDSA cycles were conducted and learning from each cycle was fed into the next adaptation of the process. PDSA cycles involved members of the public, patients, clinicians, informational technologists as well as the project manager. All PDSA cycles were initiated from patient or public ideas. Two main PDSA ramps are summarised here.

\section{PDSA cycles ramp: technical issues}

A participant was unsure if Near Me would work from their home due to 'technical' issues. A PDSA test was planned by LMac with the aim of the participant being able to use the Near Me platform. The participant was sent the link and an agreed appointment time. The call was successfully accessed and connected. Feedback from the participant was that their IT facilities at home had the correct technical specification and adequate bandwidth to use Near Me. However, the participant suggested that it may be useful to add the technical requirements to the Near Me website for public information and that having an opportunity to test before an appointment would provide user confidence that the system would work. Technical specification information was added to the Near Me website and a step was added for a line check call before the first scheduled appointment in the process. The participant also asked three friends to test the use of the Near Me platform. The participant provided feedback from others' tests. Their feedback suggested that others may not opt to use Near Me at the stage of booking an OPA as they did not have a prior opportunity (as did the participant) to test the system, and line checks were only booked after the Near Me option was selected. Participants suggested that it would be useful to 'test' the system before an appointment was due or needed. A Friday afternoon 'virtual' drop-in service was initiated to enable people to test Near Me regardless of whether they had an appointment. Other participants who tested calls suggested that it would be good to be able to talk to someone to help them troubleshoot with any technical challenges. A local support telephone number was initiated but further cycles highlighted that a team of two, with other additional workloads, was not sustainable to answer queries and provide support whenever required. National telephone support was then organised and a local Island 
charity (AbilityNet) agreed to support individuals with technical difficulties on a one-to-one basis. Telephone consultations were agreed with the participants and clinicians as a contingency plan if people experienced connectivity issues on the day of the appointment.

\section{PDSA cycles ramp: information on use}

The aim here was to ensure that participants could follow the revised instructions for use and make a successful Near Me call. Instructions had been revised based on patients' feedback prior to their use for the Near Me at Home project. A test call was set up with a participant who had a clinician virtual appointment. After a few minutes of no one answering the participant's call, they contacted the support line telephone number. It was established that although the participant thought there was a technical problem due to no one answering the call, this was due to a clinician running late and not answering the call. Learning from this cycle highlighted that patients would need information to explain that they were waiting for their call to be answered. Additional information was added to the wait screen to tell participants they were in a virtual waiting room and instructions on what to do if a call had not been connected within 15 min. Further PDSA testing of the use of the revised instructions and screen information resulted in successful use of Near Me.

\section{Stage 3: implementation}

Based on the participants testing, a future process flow map was devised and implemented (online supplementary additional file 1: process flow maps). Seven unstructured telephone interviews (five participants from initial recruitment and a further two during participants snowballing) were conducted to gather participants' experience of the codesign process for future learning. Participants were all members of the public and were asked about what motivated them to be involved in the project and their experiences of being involved in codesigning Near Me at Home. Interviews were audio recorded and transcribed. Two researchers (MB, RMac) conducted a thematic analysis based on the principles and procedures of framework analysis. Both researchers independently read the transcripts to identify emerging themes before meeting to compare, contrast and identify themes before finalising the interpretation.

\section{RESULTS}

The results include both the changes made from PDSA testing and the thematic analysis of the codesign process.

\section{Changes to the Near Me at Home processes}

The ideas generated during the inspiration and ideation phase with public participants resulted in 25 adaptations to the process. Table 1 provides a summary of the key changes. Many of these changes would never have happened without the co-design work.
Findings from the thematic analysis of the codesign process Analysis of the participant interview transcripts at stage 3 revealed interesting insights about the codesign process. Four themes were identified as important aspects of the codesign process; altruistic motivation, valuing community voices, the usefulness of the PDSA cycles and the power of 'word of mouth'.

\section{Altruistic motivation}

Participants were asked why they chose to be involved in the project. An altruistic drive to improve things for the local community, an opportunity to influence and makes changes and an interest in the topic were all identified as important factors.

The benefits that I see for the people in our community. P2

They realise how interested people here are in making sure that things are really appropriate for them. P6

Well you need to have a conscience; you need to want to feel that you want to help. P3

I think it's just if you have an interest in something P1

I'd been banging on about for years; about transporting people great distances for basically minutes of a consultation. Which could be done remotely and it's something I think is long overdue and something I personally had been very, very keen to see happening. So, I suppose I have had a bit of a vested interest over the years. P2

\section{Valuing community voices}

The important role and value of public/patient contribution and the need to consider services in relation to the local context was reaffirmed by participants. The value of real-world participants' experience was important.

I do because it's one thing sitting in an office to design something, it's quite another to use it in the field, as it were. Especially with a wide range of ages and familiarities with the technology and also the geography. P6

Well I think that's always really important, isn't it? Because they want to know, it's not just all theory but the practical working, isn't it? Because very often people can have the ideas and stuff but then they want to know how it is... and I think that's always a very good thing, isn't it? P4

Participants identified the importance of their unique perspective and felt valued as members of the local community.

Our experience, I think helps. The fact that we understand the benefits to the community. P2

But you've given us the opportunity to give you the thoughts of our wisdom. Yes, consultation is crucial. P3 
Table 1 What did the codesign process change?

\section{Ideas or learning identified by participants Change to the process}

Technical

Near Me may not be accessible for patients due Provided information about the technical specification on the Near Me to its technical specification

\section{website}

Near Me platform provider has lowered bandwidth requirements to improve accessibility - technical requirements are low

Patients' equipment may not be compatible with Near Me system

Need to provide support for patients who encounter difficulties with using Near Me

Added a 'line check' step into the process before first scheduled appointment

Telephone support in place (local number first but as a team of two insufficient, national back-up added)
Introduced Friday afternoon virtual 'drop in' sessions for anyone wanting to try out accessing Near Me for an appointment from home

Link made with charity AbilityNet who will support individuals with technical difficulties on a one-to-one basis

Concerns over security of system and privacy Increasing awareness of safeguards in place (local and national) and highlighting that there is no recording of consultations

Unexpected connectivity issues on the day of the appointment

\section{Information}

Near Me information leaflets not fully understood Posters and leaflets about NHS Near Me were tested and codesigned with participants and distributed across NHS Highland

Patients did not know what to do when their call Information added to the main NHS Near Me reception waiting screen which was not connected quickly included a phone number to call if not answered within a specific time frame Capacity doubled at the Near Me reception process by installing a second computer terminal

Provide a direct link so that once people click on Single point of access for all appointments, so specific links are not needed: their appointment it will take them directly to the https://www.nhshighland.scot.nhs.uk/NHSNearMe/Pages/Welcome.aspx receptionist
Provide a Near Me app

Patients can add a shortcut to the webpage to their phone/tablet, which is faster than an App.

\section{Patient and clinician decisions}

Video appointments are not always clinically appropriate. Concerns highlighted included patients receiving difficult news, some mental health conditions and the need for physical examination

Patients may not get a choice over whether to use Near Me or have an in-person consultation

Concerns over the technology being too difficult for some people to use

Suggestion to register patients with the Near Me service so only these patients are offered consultation using Near Me

Near Me enables patients to have a family member or friend present
Clinician makes the decision whether to offer, or not, Near Me on an individual appointment basis and the patient can choose to opt out

The method of returning appointments should be discussed between clinician and patients, allowing the patient to choose. For new appointments, patients will be contacted to allow them to opt out of the Near Me option and choose a traditional appointment

Staffed NHS Near Me rooms set up where people can go to have a member of NHS staff support them to call, that is, Local GP practice

After exploring this, it became apparent that this was not a suitable option. It would have prevented patients from being offered a Near Me appointment who had not heard of the system previously and it there was not a complete list of patients to contact to offer the service. However, learning from this initiated a new system of annotating patients records as to whether they had opted for Near Me appointments. This remains a patient choice as they can still request a physical face-to-face consultation

All clinicians are made aware of this function in training so they can offer it to patients

Patients and patient groups informed whenever there is an opportunity to discuss Near Me 
Table 1 Continued

\begin{tabular}{|c|c|}
\hline Ideas or learning identified by participants & Change to the process \\
\hline $\begin{array}{l}\text { Patient suggestion to promote NHS Near } \\
\text { Me from 'word of mouth' using the patient } \\
\text { experience }\end{array}$ & $\begin{array}{l}\text { Patient stories have been captured and shared anonymously via the press } \\
\text { and social media. A short film has been made with a patient }\end{array}$ \\
\hline $\begin{array}{l}\text { Lack of awareness among secondary care } \\
\text { clinicians - participants recommended face-to- } \\
\text { face meetings with clinicians to encourage them } \\
\text { to offer patients the Near Me option }\end{array}$ & $\begin{array}{l}\text { Every clinical service in NHS Highland was contacted and offered to meet } \\
\text { to discuss NHS Near Me. There are now } 27 \text { services providing Near Me } \\
\text { appointments, with more meetings to follow. }\end{array}$ \\
\hline $\begin{array}{l}\text { Obtain buy-in from local clinicians - patients } \\
\text { said this was essential as patients are more } \\
\text { likely to trust a local clinician whom they know }\end{array}$ & $\begin{array}{l}\text { Information sent to all GP practices across NHS Highland. Meetings held } \\
\text { at some GP practices. Difficult to visit all practices due to the number of } \\
\text { practices and geography. Alternative meeting options are being explored, } \\
\text { that is, web casting. }\end{array}$ \\
\hline $\begin{array}{l}\text { Continue to evaluate Near Me to gather further } \\
\text { feedback and adapt as required }\end{array}$ & $\begin{array}{l}\text { A patient feedback survey was added to the NHS Near Me system, which } \\
\text { pops up automatically after each call. }\end{array}$ \\
\hline
\end{tabular}

GP, general practitioner; NHS, National Health Service.

They were listening to our opinions and I think they said that they benefitted from that, from what we all contributed. P4

Linked to the importance of valuing their contributions participants reported that the facilitators appeared genuine and valued their perspectives equally.

it was like a really good team meeting, it wasn't like the girls that were involved in launching it and getting the ideas-and us; it was like we were one big group, throwing out ideas and scribbling them down, somebody saying 'oh, that's great', and bouncing off each other as well. P1

Yes, we thought they were very good and engaging, we've had lots of experience where we can say otherwise. P4

So the fact that they actually seem interested in making sure it works for people, I think is very encouraging. $\mathrm{P} 6$

Demonstrating the value of community participants by listening to their ideas helped connect and build a relationship of trust with the local community.

So to be perfectly honest with you, maybe with all the negative stuff that the NHS has had, NHS Near Me may well be one of the ways in which you rebuild confidence with the community. P3

indeed it's a lesson to many people that, that's how you do gain the confidence of people and the trust of people, you are not going to gain it if you are acting against people, as we all know. $\mathrm{P} 4$

\section{The usefulness of PDSA cycles}

Using small-scale PDSA cycles enabled their valuable contribution to be used to adapt the process without overwhelming participants. Acting on the learning from PDSA cycles, as opposed to listening only, affirmed to participants that their views were being taken seriously, that is, clearer patient information leaflets for all. All participants received a copy of table 1 to explain all the actions that had been taken, as well as discussions about individual points with the group member who raised them.

Well I haven't had to do anything complicated nor time-consuming when I had other things to do. P3

They've changed quite significantly; a lot of the literature that they've provided, the way they administer some of the Near Me stuff, so there have been changes. So again, it demonstrates that people are listening and understanding that changes have to be made. P2

I got a couple of emails from one of the Leads with 'This is what we're doing in the leaflet' and I pinged back with a few 'Perhaps we should say this or clarify that', I'm assuming others did that as well, the other people that were at the meeting. It was...quite painless! P1

If people become involved, they take more care of it, don't they? P7

\section{The power of word of mouth}

When asked about how participants thought the use of Near Me could be further spread the power of word of mouth was frequently mentioned as an important way to influence others in the local community to use of Near Me.

This is a community reluctant to use NHS24...but as this is developing word-of-mouth, people are actually pricking their ears up and prepared to give this some time. P3

Again, it's one of these things that, once it starts and people start to like it, it does snowball a bit. And that's through word-of-mouth but, again, we need to be very proactive in getting people to at least agree to consider it as an option, were the circumstances to be correct for it to be used. P2 
It would need to be word-of-mouth; I think they would need encouragement. P7

\section{LESSONS AND LIMITATIONS}

This project achieved its aim of codesigning the use of NHS Near Me to enable video consultations with specialists to take place in the patient's home on the Isle of Skye. We believe the codesign approach was essential to implement the use of Near Me at Home within this community. Public members provided insights to how the community could use Near Me at home, which would otherwise have been unknown. This reaffirms the view that patients and the public indeed hold unique perspectives about how health services can be designed to fit their communities. Yet, although partnership is identified as an important aspect of sustainable QI, the principles of codesign are infrequently applied. ${ }^{31}{ }^{32}$ Additionally, there was also a shared view between the public and the local health services that there was a need to reduce lengthy patient commutes for brief consultations. This likely aided participation and implementation as people need to believe the problem is worth addressing and the solution has potential before investing effort into the project.

Participants appeared to benefit from being treated equally and feeling valued, which helped build a trusting relationship during the codesign process. We believe the intent of professionals to ensure the system worked for the local people and the valuing of everyone's contribution was key. Demonstrating action by applying the learning from PDSA testing to revise the Near Me system also demonstrated the value of participants' contributions and built trust in those facilitating the process. A limitation of the project was the low number of participants and the fact that they were not representative and inclusive of all groups. The participants involved did not include under-represented groups, such as those with mental health problems, people with visual and hearing impairments and parents with young children. Hearing their perspective may have influenced the changes made to the use of Near Me in Skye. As always, time constraints were a limiting factor. It remains a challenge to involve a diverse group of patients and the public when making improvements. ${ }^{29}$ While the project aimed to codesign the use of the NHS Near Me video consulting platform for OPA to take place in the patient's home, adding an outcome measure of Near Me at Home use during and after this project would have provided evidence of its implementation.

The current benefits of the use of Near Me at Home nationally have accelerated exponentially due to the COVID-19 outbreak. By June 2020, the use of Near Me reached over 17000 consultations per week, with over 150000 in total in Scotland (written communication, 4 July, Digital Reform and Service Engagement Directorate, Scottish Government). Although these national data are not disaggregated between home and clinic use, it is likely that most of these consultations will be home use as nearly all clinics ceased during the COVID-19 pandemic. The Scottish Government has launched a vision to develop safe, person-centred and sustainable care through video consulting and are conducting a national public engagement exercise. ${ }^{33}$ These strategic actions are aligned to nudge theory which sets a default option automatically (in this case, Near Me VC) unless individuals (patients and clinicians) intervene and choose something different. ${ }^{34}$ Nudge theory has been used in other QI projects and likely aids sustainability. ${ }^{35}$

While the research into the effectiveness of the Near Me during COVID-19 is limited, the practical implications for expansion to Near Me at Home are obvious. Guidance has highlighted where the use would be beneficial to patients (ie, the patient is well but anxious and requires additional reassurance) and clinicians (well but self-isolating). ${ }^{36}$ Patients and clinicians currently using the system due to COVID-19 creates an opportunity, which may not have been available otherwise, for people to 'test' wider uses. While we contend that interventions cannot be simply lifted and shifted to other contexts, this unique situation enables those using Near Me to test, learn and adapt its use to their contexts.

\section{CONCLUSION}

This project successfully codesigned the use of Near Me at Home videoconsulting, through QI methodologies to address a key issue for the community of Skye. The current level of dissatisfaction, travelling in excess of 200 miles for a brief OPA, provided the ideal context to introduce the Near Me video consulting solution and assess the benefits of codesigning the change. However, although rurality was a driver for developing Near Me, it has quickly become apparent that other barriers to attending faceto-face appointments exist in urban areas, such as work, caring responsibilities and mobility issues. By codesigning the use of Near Me with people living in Skye, multiple adaptations were made to address existing limitations of the system and create a sense of ownership and trust with local community participants. We do not know whether the revised system will be fully adopted by the local community, but we strongly believe it has a greater chance of spread and sustainability through this collaborative venture. The lessons learnt here from testing and adapting with the public are likely to be useful for others embarking on codesign approaches to improve quality. Twitter Michelle Beattie @BeattieQi and Clare Morrison @clareupnorth

Acknowledgements The authors would like to thank every member of the codesign group who made this project possible and helped shape the use of NHS Near Me in Skye. Special thanks to Laura MacDonald, Project Administrator and TEC Support who arranged meetings, provided demonstrations and facilitated some testing of Near Me.

Contributors This project was codesigned by $\mathrm{CM}$ and MB. MB obtained ethical approval. CM and MB facilitated workshops. RM conducted telephone interviews. All authors contributed to the paper and agreed the final version.

Funding The project was awarded $£ 30000$ through the Q Exchange funding programme, Health Foundation. The Near Me platform is funded for use in NHS Scotland by the Scottish Government's Technology Enabled Care programme. 
Competing interests None declared.

Patient and public involvement Patients and/or the public were involved in the design, or conduct, or reporting, or dissemination plans of this research. Refer to the Methods section for further details.

Patient consent for publication Not required.

Ethics approval Although this was a quality improvement project, we sought and gained ethical approval based on advice from our local Research and Development Office. A submission to the Integrated Research Application System (IRAS) determined proportionate review (IRAS ID 257115) and subsequent REC approval (REC Ref: 18/ LO/2174).

Provenance and peer review Not commissioned; externally peer reviewed.

Data availability statement All data relevant to the study are included in the article.

Open access This is an open access article distributed in accordance with the Creative Commons Attribution Non Commercial (CC BY-NC 4.0) license, which permits others to distribute, remix, adapt, build upon this work non-commercially, and license their derivative works on different terms, provided the original work is properly cited, appropriate credit is given, any changes made indicated, and the use is non-commercial. See: http://creativecommons.org/licenses/by-nc/4.0/.

\section{REFERENCES}

1 Scottish Government. Achieving Sustainable Quality in Scotland's Healthcare: A '20:20' Vision, 2012.

2 Ham C, Dixon A, Brooke B. Transforming the delivery of health and social care. London: Kings Fund Report, 2012.

3 Robertson R, Wenzel L, Thompson J. Understanding NHS financial pressures: how are they affecting patient care? 2017.

4 Luchinskaya D, Simpson P, Stoye G. Uk health and social care spending. Institute for fiscal studies, 2017.

5 Donnellan F, Hussain T, Aftab AR, et al. Reducing unnecessary outpatient attendances. Int J Health Care Qual Assur 2010;23:527-31.

6 Pencheon D. Developing a sustainable health care system: the United Kingdom experience. Med J Aust 2018;208:284-5.

7 NHS Highland. About NHS highland. Available: http://www. nhshighland.scot.nhs.uk/AboutUs/Pages/AboutUs.aspx [Accessed 11 Mar 2020].

8 Novel coronavirus (COVID-19) primary medical care commissioning guidance, 2020. Available: https://www.england.nhs.uk/coronavirus/ wp-content/uploads/sites/52/2020/03/Commissioner-guidancelocal-requests-to-suspend-online-booking_050320.pdf

9 NHS Scotland. Transforming outpatient services adopt advice only, referral feedback response and develop clinical dialogue, 2014.

10 Avienda. Guidance on the use of videoconferencing in health care. Available: http://www.webcitation.org/50124PNcr

11 Telehealth and Telecare Aware. Nhs Scotland launches attend anywhere video consult trial, 2016. Available: http://telecareaware. com/tag/attend-anywhere/

12 Health_Foundation. Pharmacy anywhere. Available: https://www. health.org.uk/improvement-projects/pharmacy-anywhere [Accessed 21 Jul 2020].

13 Nilsen P, Bernhardsson S. Context matters in implementation science: a scoping review of determinant frameworks that describe contextual determinants for implementation outcomes. BMC Health Serv Res 2019;19:189.

14 Øvretveit J. How does context affect quality improvement? perspectives on context: a selection of essays considering the role of context in successful quality improvement. London: The Health Foundation, 2014: 59-85.

15 Dixon-Woods M. The problem of context in quality improvement. perspectives on context. London: Health Foundation, 2014: 87-101.

16 Coles E, Anderson J, Maxwell M, et al. The influence of contextual factors on healthcare quality improvement initiatives: a realist review. Syst Rev 2020;9:1-22.

17 Hjelmfors L, Strömberg A, Friedrichsen M, et al. Using co-design to develop an intervention to improve communication about the heart failure trajectory and end-of-life care. BMC Palliat Care 2018;17:85

18 Batalden P. Getting more health from healthcare: quality improvement must acknowledge patient coproduction-an essay by Paul Batalden. BMJ 2018;1:k3617.

19 Newbronner L, Chamberlain R, Borthwick R, et al. Sustaining and spreading self-management support: lessons from Co-creating health phase 2. London: Health Foundation, 2013: 84.

20 Harris MA, Freeman KA, Duke DC. Seeing is believing: using Skype to improve diabetes outcomes in youth. Diabetes Care 2015;38:1427-34.

21 Selzler A-M, Wald J, Sedeno M, et al. Telehealth pulmonary rehabilitation: a review of the literature and an example of a nationwide initiative to improve the accessibility of pulmonary rehabilitation. Chron Respir Dis 2018;15:41-7.

22 Verhoeven F, van Gemert-Pijnen L, Dijkstra K, et al. The contribution of teleconsultation and videoconferencing to diabetes care: a systematic literature review. J Med Internet Res 2007;9:5.

23 Greenhalgh T, Shaw S, Wherton J, et al. Real-World implementation of video outpatient consultations at macro, meso, and micro levels: mixed-method study. J Med Internet Res 2018;20:4.

24 Hendy J, Chrysanthaki T, Barlow J, et al. An organisational analysis of the implementation of telecare and telehealth: the whole systems demonstrator. BMC Health Serv Res 2012;12:403.

25 May CR, Finch TL, Cornford J, et al. Integrating telecare for chronic disease management in the community: what needs to be done? BMC Health Serv Res 2011;11:131.

26 Ritchie LD. Independent external view of Skye, Lochalsh and South West Ross out of hours services, 2018.

27 Vennik FD, van de Bovenkamp HM, Putters K, et al. Co-production in healthcare: rhetoric and practice. Int Rev Adm Sci 2016;82:150-68.

28 IDEO.org (no date). What is human-centred design? Available: http:// www.designkit.org/human-centered-design [Accessed 13 Apr 2020]

29 Ocloo J, Matthews R. From tokenism to empowerment: progressing patient and public involvement in healthcare improvement. BMJ Qual Saf 2016;25:626-32.

30 Taylor MJ, McNicholas C, Nicolay C, et al. Systematic review of the application of the plan-do-study-act method to improve quality in healthcare. BMJ Qual Saf 2014;23:290-8.

31 Barson S, Doolan-Noble F, Gray J, et al. Healthcare leaders' views on successful quality improvement initiatives and context. $J$ Health Organ Manag 2017;31:54-63.

32 Steen M, Manschot M, De Koning N. Benefits of co-design in service design projects. Int J Des 2011;5:53-60.

33 Technology Enabled Care. Use of near me in the future health and care services. Available: https://www.nearme.scot/wp-content/ uploads/2020/06/near-me-vision-public-june-20.pdf

34 Leonard TC, Richard H, Thaler CR. Sunstein, Nudge: improving decisions about health, wealth, and happiness, 2008.

35 Shakespeare T, Fehlberg M, Slejko T, et al. Successful use of "Choice Architecture" and "Nudge Theory" in a quality improvement initiative of analgesia administration after Caesarean section. J Eval Clin Pract 2019;25:125-9.

36 Greenhalgh T, Morrison C, Koh Choon Huat G, IRIHS Research Group. Video consultations: a guide for practice. University of Oxford. Available: https://bjgplife.com/wp-content/uploads/2020/03/ Video-consultations-a-guide-for-practice.pdf 